\title{
BMJ Open Inner conflict in patients receiving oral anticancer agents: a qualitative study
}

\author{
Kaori Yagasaki, ${ }^{1}$ Hiroko Komatsu, ${ }^{1}$ Tsunehiro Takahashi ${ }^{2}$
}

To cite: Yagasaki K, Komatsu H, Takahashi T. Inner conflict in patients receiving oral anticancer agents: a qualitative study. BMJ Open 2015;5:e006699. doi:10.1136/bmjopen-2014006699

- Prepublication history and additional material is available. To view please visit the journal (http://dx.doi.org/ 10.1136/bmjopen-2014006699).

Received 21 September 2014 Revised 22 December 2014 Accepted 21 January 2015
CrossMark

\footnotetext{
${ }^{1}$ Faculty of Nursing and Medical Care, Keio University, Tokyo, Japan

2Department of Surgery, Keio University School of Medicine, Tokyo, Japan
}

Correspondence to Dr Kaori Yagasaki; yagasaki@sfc.keio.ac.jp

\section{ABSTRACT}

Objectives: To explore the experiences of patients receiving oral anticancer agents.

Design: A qualitative study using semistructured interviews with a grounded theory approach.

Setting: A university hospital in Japan.

Participants: 14 patients with gastric cancer who managed their cancer with oral anticancer agents.

Results: Patients with cancer experienced inner conflict between rational belief and emotional resistance to taking medication due to confrontation with cancer, doubt regarding efficacy and concerns over potential harm attached to use of the agent. Although they perceived themselves as being adherent to medication, they reported partial non-adherent behaviours. The patients reassessed their lives through the experience of inner conflict and, ultimately, they recognised their role in medication therapy.

Conclusions: Patients with cancer experienced inner conflict, in which considerable emotional resistance to taking their medication affected their occasional nonadherent behaviours. In patient-centred care, it is imperative that healthcare providers understand patients' inner conflict and inconsistency between their subjective view and behaviour to support patient adherence.

\section{INTRODUCTION}

With the development of oral anticancer agents, adherence to medication regimens is vital to maximisation of benefits and minimisation of risks. Oral chemotherapy is the standard treatment for gastric cancer in Japan to prevent recurrence and improve survival. ${ }^{1}$ However, patients with gastric cancer who have undergone gastrectomy often suffer from dumping symptoms, ${ }^{2}$ and refuse medication ${ }^{3}$ and discontinue its use due to side effects. ${ }^{4}$ Increased risks of recurrence and disease progression are prevalent in non-adherent patients with gastric cancer.

Healthcare providers often assume that patients adhere to their oral anticancer agent regimens because of their lifethreatening illness, and they do not specifically ask their patients about adherence during consultations. ${ }^{5}$ However, Partridge et $a t^{6}$ warn, 'Adherence should never be assumed, even in oncology' in their review article on medication adherence. In fact,

\section{Strengths and limitations of this study}

- This is one of the few studies in which patients receiving oral anticancer agents have described their behaviours, including non-adherent behaviours, and what they thought and felt about their medication management.

- The study revealed inner conflict between rational belief and emotional resistance, which affected partial non-adherence, and inconsistency between subjective view (perceived adherence) and behaviour (partial non-adherence) in patients with cancer.

- The findings have implications for practice and future research to develop patient-centred care for patients receiving oral anticancer agents.

- Some of the present findings may reflect sample effects in a single institution. Women and patients with other types of cancer in other settings were under-represented in this study.

underadherence and overadherence have both been reported. ${ }^{7}$ Some patients forget, intentionally skip, or are confused about when and how to take their medication. ${ }^{9}$

There are two types of non-adherence. Intentional non-adherence is an active decision not to take medication as prescribed, whereas unintentional non-adherence is a passive process in which the patient fails to adhere to prescribing instructions due to forgetfulness, carelessness, or the complexity of a medication regimen. ${ }^{10-12}$ Causes of intentional nonadherence include lifestyle, negative emotions and greater severity of side effects, ${ }^{11}$ while sociodemographic factors, such as male gender and middle age, are mainly associated with unintentional non-adherence. ${ }^{10}$ Patients' beliefs about medication are stronger predictors of adherence than clinical and sociodemographic factors. ${ }^{13}$ A meta-analysis indicates the importance of patient support based on the NecessityConcerns Framework, which states that patients' balance of their perceived need of the treatment (Necessity beliefs) and concerns about the potential adverse consequences (Concern) affects adherence. ${ }^{14} \mathrm{~A}$ synthesis of qualitative studies of medication in chronic diseases also concludes that people are reluctant to take 
medicine because of concerns about the medicine, including tolerance, long-term effects and stigma. ${ }^{15}$

Recently, patients with cancer have had new tasks to perform, including self-administration, self-monitoring and self-management; ${ }^{916}{ }^{17}$ however, they are often vulnerable, with threatened self-identities, fear of death and anxiety concerning a process full of uncertainty. ${ }^{18}$ The illness process often leads to psychological vulnerability and loss of personal power, and demands that the patient gains control over these psychological effects. ${ }^{19}$ Healthcare providers tend to promote adherence simply based on whether the patient is adherent or nonadherent; however, patient support should be based on individual real needs with a deep understanding of their thoughts, feelings and behaviours. We conducted a qualitative study to explore the experiences of patients with cancer receiving oral anticancer agents and their perceptions regarding taking their medication.

\section{METHODS}

\section{Study design}

We conducted a qualitative study with patients diagnosed with gastric cancer, to gain knowledge of their lived experiences with taking medication, using Strauss and Corbin's grounded theory approach. ${ }^{20}$ Semistructured interviews were used to explore individual participants' perspectives, as only patients know how they manage their medication and illnesses in their daily lives.

\section{Participants}

Patients with advanced gastric cancer (defined as 'tumour invasion beyond the muscularis propria'), ${ }^{21}$ who were receiving more than one cycle of oral anticancer agents following surgery were included in the study. Gastric cancer is one of the commonest cancers, and the second leading cause of cancer death in Japan. ${ }^{22}$ Since the evidence supports the safety and efficacy of oral anticancer agents (TS-1), ${ }^{1}$ it is important to encourage patients to adhere to oral chemotherapy. Owing to the presence of numerous older patients with cancer, there was no cut-off age in this study. We excluded patients who had communication problems (difficulties in speaking and understanding about symptoms and medication) and significant physical discomfort including side effects, anxiety or depression, assessed by the primary physician.

The study was explained to the participants, who were recruited at routine clinical appointments in a university hospital in Tokyo. Then, the first author (KY) again explained the details of the study to patients who were still interested in the study, including the purpose, interview method and the voluntary nature of the study. Lastly, informed consent was obtained from patients who agreed to participate in the study.

\section{Data collection}

We developed a semistructured interview guide based on the literature regarding barriers to oral anticancer medication adherence. ${ }^{6} 923$ The first author (KY) conducted all individual interviews in Japanese using the interview guide at a meeting room in Keio University Hospital in Tokyo between May and September 2013. The mean interview time was $25 \mathrm{~min}$ (range 15-50). Interview topics included participants' perspectives on medication management and side effects. In addition, we asked participants how they took their medication in their daily lives, including taking it in the workplace, and how they felt about it (for the interview schedule, see online supplementary file 1 ).

For purposive sampling, we established inclusion criteria in consideration of current practice at the outpatient clinic, and gathered demographic and medical backgrounds of research participant candidates to collect data relevant to adherence of patients with gastric cancer. Then, we performed purposive sampling based on the inclusion criteria. We began interviews with open questions (eg, 'How would you describe your experience of taking medication?') and collected data widely using a semistructured interview guide. After our initial data collection for two participants and analysis, we employed theoretical sampling. We collected data focusing on important phenomena (eg, attitude towards medication as essential drug, a sense of duty towards medication, emotional resistance and partial nonadherence) in the study. We added new interview questions based on the analysis. In the sampling for selective coding after the 10th participant, KY wrote a story line, examined relationships among categories and led to a potential core category. However, we still needed more data on 'emotion when forgetting to take medication' and 'meaning of taking anticancer agents'. Therefore, we continued theoretical sampling. We revised the story line, re-examined relationships among the categories, and identified the core category. Finally, when we collected data from 14 participants, the data reached theoretical saturation; there were no further data to lead a new category, and the relationships between categories were established. The research team had regular meetings to review the data, and discuss interpretations during the sampling and analysis process.

\section{Data analysis}

The data were analysed according to grounded theory methodology. ${ }^{20}$ All interviews were audio recorded and transcribed verbatim. The data were analysed using the constant comparative method: in open coding, line-by-line coding was conducted, and concepts were labelled and categorised. During axial coding, subcategories were derived from identifying relationships among the labels, and categories were related to subcategories (for an example of the analysis process, see online supplementary file 2). Using selective coding, a core category was identified by relating it to other categories. Once the themes and quotations to support them had been finalised, they were translated into English by a professional translator, and edited by a 
native English speaking editor. Finally, the authors validated the translation from Japanese to English.

The rigour of the study was confirmed by establishing credibility, dependability and confirmability. ${ }^{24}$ The researchers reviewed the data, and agreed with the codes and themes identified. The second author (HK) confirmed the results of the analysis performed by the first author (KY).

\section{RESULTS}

All patients who had been provided with the research overview $(\mathrm{N}=14)$ agreed to participate in the study. The mean age of the participants was 63.4 years (range $43-80$ years). Two participants were 80 years old but vigorous: one still owned and ran his own company, and another exercised five times a week. All participants were fully active and managed their medication themselves (table 1).

\section{Inner conflict in patients with cancer (core category)}

Inner conflict in patients with cancer emerged as a core category with five relevant categories (Rational belief, Emotional resistance, Subjective view: Perceived adherence, Behaviour: Partial non-adherence, and Recognition of one's role in medication therapy) (table 2). First, the inner conflict occurred between patients' rational beliefs and emotional resistance; they felt a sense of duty to survive and wanted to take medication as prescribed in a trustful relationship with the physician, but at the same time, they had negative emotions due to confrontation with cancer, doubt regarding efficacy and concern over potential harm. Emotional resistance outweighing their rational beliefs triggered partial non-adherent behaviours. Second, the inner conflict caused a distortion in thought and denial of their partial non-adherent behaviours. The patients with cancer tried to ensure that their necessity beliefs for survival and behaviours were consistent, and,

\begin{tabular}{lc} 
Table 1 Patient characteristics & \\
\hline & $\mathbf{( N = 1 4 )}$ \\
\hline Mean age (range) & $63.4(43-80)$ \\
Gender $\mathrm{n}(\%)$ & $11(78.6)$ \\
Male & $3(21.4)$ \\
Female & $3(21.4)$ \\
Stage at diagnosis n (\%) & $8(57.1)$ \\
Stage Ilb & $3(21.4)$ \\
Stage III & $6(42.9)$ \\
Stage IV & $7(50.0)$ \\
Job status $\mathrm{n}(\%)$ & $1(7.1)$ \\
Full-time & \\
Retired or semiretired & $10(71.4)$ \\
Housewife & $2(14.3)$ \\
Marital status $\mathrm{n}(\%)$ & $2(14.3)$ \\
$\quad$ Married (1 was widowed) & \\
Divorced & \\
Unmarried & \\
\hline
\end{tabular}

therefore, they maintained their conscious thought as being adherent, while they reported intentional as well as unintentional non-adherence episodes. This caused the inconsistency between their subjective views and behaviours. Third, the participants reassessed their lives through the experience of cancer and inner conflict, and they ultimately accepted their life as it was. When the gap between their rationality and emotions is narrowed, they recognised their role in medication therapy.

\section{Rational belief}

The diagnosis of cancer was a shocking event; the participants suddenly realised that life is finite. To ensure their survival, they had a sense of duty to adhere to medication regimens, because they knew that anticancer agents could potentially extend their lives. Otherwise, their own mortality could become a reality:

If I do not take medicine, I do not think I will be able to live (56-year-old female; Participant E).

It is different from common drugs such as cold medicine and stomach medicine. So I manage to take it because I feel I have to take it. I think I am carefully managing it compared with other drugs (47-year-old male; Participant D).

The participants perceived needs for medication, and used self-motivation to follow their medication regimens:

I stir myself. It may be my motivation. It's my obligation. I have to do it. I have to take medicine, so I do (55-year-old male; Participant B).

I know I have to take it. I just make the best of it (76-year-old male; Participant A).

Table 2 Common themes in patients taking oral anticancer agents

\begin{tabular}{|c|c|c|}
\hline $\begin{array}{l}\text { Core } \\
\text { category }\end{array}$ & Categories & Subcategories \\
\hline \multirow[t]{8}{*}{$\begin{array}{l}\text { Inner } \\
\text { conflict }\end{array}$} & Rational belief & $\begin{array}{l}\text { A sense of duty to } \\
\text { survive } \\
\text { Trust in physician }\end{array}$ \\
\hline & Emotional resistance & $\begin{array}{l}\text { Confrontation with } \\
\text { cancer }\end{array}$ \\
\hline & & $\begin{array}{l}\text { Doubt regarding } \\
\text { efficacy }\end{array}$ \\
\hline & & $\begin{array}{l}\text { Concern over } \\
\text { potential harm }\end{array}$ \\
\hline & $\begin{array}{l}\text { Subjective view: } \\
\text { perceived adherence }\end{array}$ & $\begin{array}{l}\text { Perceived } \\
\text { adherence }\end{array}$ \\
\hline & $\begin{array}{l}\text { Behaviour: partial } \\
\text { non-adherence }\end{array}$ & $\begin{array}{l}\text { Intentional } \\
\text { non-adherence }\end{array}$ \\
\hline & & $\begin{array}{l}\text { Unintentional } \\
\text { non-adherence }\end{array}$ \\
\hline & $\begin{array}{l}\text { Recognition of one's } \\
\text { role in medication } \\
\text { therapy }\end{array}$ & $\begin{array}{l}\text { Acceptance of life } \\
\text { as it is }\end{array}$ \\
\hline
\end{tabular}


The participants' rational belief was also affected by their trust in the physicians. A trustful relationship with the physician was one of the motivations for continuing treatment.

(It is important) to take medication and receive intravenous therapy, which means not stopping treatment and trusting the physician. That's it (56-year-old female; Participant E).

I really trust my physician and receive treatment. He is a very good physician for me. I have to do my part too. I cannot betray his trust (64-year-old female; Participant G).

\section{Emotional resistance}

The opposite side of rational belief in inner conflict was emotional resistance. Although the participants all knew what to do, they had considerable emotional resistance to taking their medication due to confrontation with cancer, doubt regarding efficacy and concern over potential harm attached to use of the agent. As these emotions constantly resurfaced, they experienced conflicting emotions with respect to whether they should take medication.

First, every time the participants took their medication, they had to acknowledge that they were suffering from cancer. It was depressing.

So far, there are no side effects. But I feel depressed when I take the agent. Maybe it is only a sensory impression (80-year-old male; Participant F).

The participants knew that taking medication was not a painful procedure, but they felt uncomfortable doing so, because taking the anticancer agent represented the reality of the situation-I have cancer.

(The anti-cancer agent is) different from other agents. I am very nervous about taking it. It's a distinct feeling (56-year-old female; Participant E).

Taking TS-1® is no big deal for me, but it is depressing to think that $I$ have to take this anti-cancer agent for four weeks. I tell my friend that it (treatment duration) varies so I have to take it anyway. Take it easy. If it's like 'take it or no way,' I will be depressed (47-year-old male; Participant D).

The break between treatments was a relief for the participants, because they did not have to think about cancer:

I can only forget about the disease during the break. You know, it's four weeks on and one week off. I say aloud 'I'm happy!' (64-year-old female; Participant G).

Second, all of the participants provided informed consent to undergo oral chemotherapy, but they still doubted the medication's efficacy. They suggested that the agent could have been effective for others but not for them.
The outcome may be the same anyway, even if I do not take medication (76-year-old male; Participant L).

The efficacy is not so great. It is said to expect about $10 \%$ improvement, but I assume that it declines over time (57-year-old female; Participant $\mathrm{H}$ ).

Third, the participants were concerned over potential harm from medication. They were aware that potent medications usually have side effects and affect individuals differently. Although none of the participants reported experiencing severe side effects, they had strong concerns about side effects and the impact the treatment would have on their lives.

One man received information from his physician that indicated that oral anticancer agents could improve his chance of survival from $70 \%$ to $80 \%$, but he wondered what it would mean for him and was concerned about the impact the agent would have on his life:

In short, it is a $10 \%$ improvement. It's a balance with side effects. I wonder whether the side effects are really bad and if the agent is dramatically effective. I will continue to take it at any price while enduring distressing side effects, if it is effective, but it may not be really effective for me, so it's a balance with side effects (76-year-old male; Participant L).

One woman questioned the significance of oral anticancer agents while balancing the expectation of treatment effects against toxicity:

So what? For example, to reduce the rate of metastasis by $10 \%$, the agent kills normal cells as well. Is it good for me? I am concerned about it (57-year-old female; Participant $\mathrm{H})$.

\section{Subjective view: perceived adherence}

All of the participants perceived themselves as adherent to medication as prescribed. As the participants acknowledged the importance of medication, based on their rational beliefs, they strongly denied their attitudes to non-adherence:

Forget to take medication? Never! It's different from cold medicine. I don't think that people who are taking this kind of medicine ever forget it (56-year-old female; Participant E).

I never understand people who have forgotten to take it (76-year-old male; Participant A).

The majority of the participants managed the medication in their own ways, and they emphasised how easy taking medication was, stating that they had never broken the rules:

It's easy to take medication. I only have to take it after morning and evening meals. I put the medicine on the table. I have never been non-adherent (46-year-old male; Participant G). 
One man said that he had always taken his medication as prescribed, but he also said that he had not taken it on the day of the interview. However, he was unaware of the contradiction:

Oh, I never skip medication. Well, this morning, I skipped it, because I left home early (70-year-old male; Participant J).

\section{Behaviour: partial non-adherence}

There was divergence between the head (active participation in therapy) and the heart (temptation to avoid taking medication). The participants were sometimes driven more by emotion than reason:

I don't know why, but sometimes I don't want to take it...' (64-year-old female; Participant G).

Umm, I really wish I could skip it (medication). I have such irresistible feelings (47-year-old male; Participant D).

In fact, the participants reported intentional and unintentional partial non-adherence; however, none of the participants discontinued the medication completely.

Some patients reported occasionally skipping their medication intentionally. One of the participants was very strict regarding medication management on weekdays. However, at the weekend, he did not care about it as much as he did during the week.

I want to have a day off (medication) on Saturdays because I sometimes drink beer in the morning. I try to not to overlap (alcohol and medicine), but sometimes they do overlap, so I skip it (medication) (47-year-old male; Participant D).

Other participants also occasionally skipped their medication on purpose, but they justified their nonadherent behaviour by describing it as an exception due to a change in routine or special occasion. Participant $\mathrm{C}$ insisted that it was easy to take the medicine and stated that he had never broken his rule, but he later reported that he skipped his medication when he entertained his clients, because he did not want to spoil the mood at dinner:

I don't take medication when I entertain my clients or drink alcohol (46-year-old male; Participant C).

Partial non-adherence occurred through skipping medication (the skipped medicine was left unused) or modifying the medication schedule. One participant usually paid attention to overdoses and underdoses but changed the treatment schedule according to his own judgment by adding a day off:

The doctor told me one week on and one week off, but, I often take it for 6 days and then take 8 days off (80-year-old male; Participant F).
The participants also experienced unintentional nonadherence, which mainly involved forgetting to take the medication:

It's mostly at the weekend (when the patient forgets to take medication) (43-year-old male; Participant M).

I usually forget to take medication at night. I sometimes fall asleep right after a meal. I recognise that I've forgotten my medication, but it's too late. I don't know whether I should take it or not. In such cases, I decide not to take it (67-year-old male; Participant K).

A change in regimen sometimes confused patients. When the regimen was changed, one man continued to take his medication three times, instead of twice, per day:

I thought it was the same, so I took medicine every morning, day, and night. After one week passed, I recognised my mistake, because the medicines were consumed so fast (55-year-old male; Participant B).

\section{Recognition of one's role in medication therapy}

Through the experience of inner conflict, the patients reassessed their lives with cancer, and ultimately accepted their lives as they were. Even if the treatment is not effective, they will accept the fact.

If recurrence does occur, that's life (80-year-old male; Participant F).

I hope the agent works well, but if it does not work for me, I will accept it (70-year-old male; Participant N).

I believe that I made the best decision for me (70-year-old male; Participant N).

When the participants acknowledged the situation where there were positive and negative aspects, taking the medication was no longer stressful:

No more (frustration). Now I feel I am beating it (70-year-old male; Participant J).

As mentioned earlier, the 57-year-old female participant heard that the prognosis for her type of cancer was poor, and she struggled to find a solution by balancing the possibility of a $10 \%$ improvement against the potential harm to her body. She reassessed her values and the meaning of the treatment and, eventually, she found her role in treatment.

It's about my body. So I have to do what I should do (57-year-old female; Participant $\mathrm{H}$ ).

Once such patients recognise their roles in medication therapy, they will more fully commit to treatment.

\section{DISCUSSION}

The participants in our study experienced inner conflict between rational belief and emotional resistance to 
taking medication due to confrontation with cancer, doubt regarding efficacy and concerns over the potential harm of drugs. In contrast to their acknowledgement of the importance of treatment and perceiving themselves as adherent, both intentional and unintentional partial non-adherence was reported. There were apparent contradictions between their subjective view (perceived adherence) and behaviours (partial non-adherence). The participants reassessed their lives through the experience of inner conflict, and ultimately recognised their roles in medication therapy.

Our study is one of the few to focus on thoughts, feelings and behaviours with respect to medication adherence of patients with cancer, including patient reports of their partial non-adherence. Our findings offer further insight into the interpretation of non-adherent behaviours in patients with cancer. There are several limitations with respect to the generalisation and interpretation of the findings. As with all qualitative studies, our sample size was small. In addition, because sociodemographic factors, such as gender and age, are mainly associated with nonadherence, ${ }^{10} 25$ some sample effects may have been involved, including those of using a single institution, examining a single type of cancer, and the inclusion of older patients and a higher proportion of men. Women and patients with other types of cancer in other settings were under-represented in this study. The mean interview time was quite short because one of the participants gave us short answers, and ended the interview in $15 \mathrm{~min}$. We included his data to the analysis because his comments were very important. After excluding this participant, the interviews ranged from 30 to $50 \mathrm{~min}$. We collected necessary data and achieved theoretical saturation. However, the depth and amount of the data might be limited. When 'emotional resistance' outweighs 'rational belief' for a prolonged time, non-adherence may occur. However, full nonadherence data were not included in this study because no patients discontinued their medication.

Patient adherence to medication regimens is widely studied as an important research area in modern oncology, which include surveys on practice, ${ }^{16}{ }^{26}$ factors affecting adherence, ${ }^{10-12} 23252728$ and interventions. ${ }^{17} 29$ Our results support the balance theory of the Necessity-Concerns Framework ${ }^{13}{ }^{14}$ in a qualitative study of the Asian population with gastric cancer. Our study illustrates how the balance between the necessity beliefs and concerns is disrupted, and the imbalance results in partial non-adherent behaviours in patients' words. Although the patients in the present study wanted to actively participate in the therapy based on their rational beliefs, emotional resistance sometimes outweighed rational beliefs. The concerns included potential harm and doubt of patients' personal need for their medication, and were consistent with those in the previous study of intentional non-adherers with chronic conditions who had stronger concerns than their necessity beliefs. ${ }^{30}$ The previous qualitative study addresses patients' considerable sacrifices behind the necessity beliefs outweighing the concerns that women with breast cancer sought to be adherent to adjuvant endocrine therapy despite a range of side effects. ${ }^{31}$ Overadherence and the impact of experiencing side effects on adherence are important; however, these issues remain unexplored in our study because there were no reports of overadherence or underadherence due to side effects.

In addition to the balance between the necessity beliefs and concerns, we also found the wavering psyche and inner conflict caused a distortion in the patients' thought and denial of their partial non-adherent behaviour. Negative emotions distort people's logical rationality. ${ }^{32}$ The inconsistency between their thoughts and behaviours is probably related to a defense mechanism in which people use denial to protect against experiencing excessive anxiety in serious illness. ${ }^{33}$ Their partial non-adherent behaviours conflict with the necessity beliefs that are integral to their survival. As cancer is a life-threatening illness, they maintain their subjective view (conscious thought) as being adherent, but some of the patients actually skipped or modified their medication occasionally. Patients' behaviours do not always coincide with what they say, and this inconsistency may occur at an unconscious level, as shown in the strong denial of non-adherence to medication regimens. Consequently, a majority of non-adherent patients with cancer belong to partial non-adherence. Uncertainty and fear of death or recurrence are always associated with cancer. ${ }^{34}$ Similar to fear of recurrence triggered by clinic visits and other healthcare-related activities, ${ }^{35}$ the anticancer agent reminded the patients of cancer, evoking negative emotions. Owing to constantly emerging negative emotions, patients' thoughts and behaviours are not always consistent while swinging like a pendulum between their opposing beliefs and feelings.

If adherence involves taking medication as prescribed, and non-adherence involves failing to take any prescribed medicines, all other patterns can be considered partial adherence or partial non-adherence. All reported non-adherent behaviours in this study were occasional and regarded as partial non-adherence. Most reasons for the partial non-adherence that are consistent with previous studies are as follows: special occasions and changes to routine such as different sleeping times, drinking alcohol and socialising for intentional non-adherence, ${ }^{11}$ and forgetting and making careless mistakes for unintentional non-adherence. ${ }^{10} 112836$

Patients with cancer live with a paradox; they often find new meaning, purpose and value in their lives, ${ }^{37}$ and these positive changes are associated with their reflections on their suffering during treatment. ${ }^{38}$ Positive affirmation helps the patient to recognise his or her role in treatment and cope with the disease more effectively through active acceptance, adjustment of physical and psychosocial consequences, and reconciliation with life and death. ${ }^{39} 40$

The findings have implications for practice and future research to develop patient-centred care for patients 
receiving oral anticancer agents. Since patients' inner conflict affects adherence, nurses should take a personalised approach to individual patients by paying attention to the conflict behind non-adherent behaviours rather than simply focusing on adherence or non-adherence. Understanding patients' rational beliefs and emotional resistance helps assessing potential partial nonadherence, and planning preventive interventions.

Healthcare providers should be aware that their relationships with patients have an impact on medication adherence. A trustful relationship with a physician is one of the factors that contribute to adherence. ${ }^{23}{ }^{41}$ There is an urgent agenda to establish a routine monitoring system for patients receiving oral anticancer agents beyond the boundaries of healthcare providers.

\section{CONCLUSIONS}

Not following prescribed regimen in cancer appears as irrational behaviour to healthcare providers, but each patient has a compelling reason for not taking medication. Once the underlying issue is revealed, it leads to opportunities to improve medication adherence. Understanding patients' inner conflict between rational beliefs and emotional resistance facilitates sharing problems with patients, and considering the inconsistency between their subjective view, and behaviour helps healthcare providers to develop effective interventions. These patient-centred approaches are fundamental to support patient adherence.

\section{Acknowledgements The authors are grateful to all of the participants.}

Contributors KY designed the study, collected, analysed and interpreted the data, and drafted the manuscript. HK made substantial contributions to the study design, sampling, interpretation of the data and preparation of the manuscript. TT contributed to the recruitment and sampling process, and supervised the collection of data and preparation of the manuscript.

Funding This work was funded by a research grant from Japan Society for the Promotion of Science KAKENHI (grant number 23593257).

\section{Competing interests None declared.}

Ethics approval This study was approved by the Internal Review Board of Faculty of Nursing and Medical Care, Keio University (No. 204) and Keio University School of Medicine (No. 2013-035).

Provenance and peer review Not commissioned; externally peer reviewed.

Data sharing statement Additional data can be accessed via the Dryad data repository at http://datadryad.org/ with the doi:10.5061/dryad.jc3s8.

Open Access This is an Open Access article distributed in accordance with the Creative Commons Attribution Non Commercial (CC BY-NC 4.0) license, which permits others to distribute, remix, adapt, build upon this work noncommercially, and license their derivative works on different terms, provided the original work is properly cited and the use is non-commercial. See: http:// creativecommons.org/licenses/by-nc/4.0/

\section{REFERENCES}

1. Sakuramoto S, Sasako M, Yamaguchi T, et al. ACTS-GC Group. Adjuvant chemotherapy for gastric cancer with S-1, an oral fluoropyrimidine. N Engl J Med 2007;1:1810-20.

2. Mine S, Sano T, Tsutsumi K, et al. Large-scale investigation into dumping syndrome after gastrectomy for gastric cancer. J Am Coll Surg 2010;211:628-36.
3. Teshima S, Saito T, Endo A, et al. Problems of adjuvant chemotherapy with S-1 for gastric cancer. Gan To Kagaku Ryoho 2010;37:255-8 (Japanese).

4. Chou WC, Chang CL, Liu KH, et al. Total gastrectomy increases the incidence of grade III and IV toxicities in patients with gastric cancer receiving adjuvant TS-1 treatment. World J Surg Oncol 2013;11:287.

5. Regnier Denois V, Poirson J, Nourissat A, et al. Adherence with oral chemotherapy: results from a qualitative study of the behaviour and representations of patients and oncologists. Eur J Cancer Care 2011;20:520-7.

6. Partridge $\mathrm{AH}$, Avorn J, Wang PS, et al. Adherence to therapy with oral antineoplastic agents. J Natl Cancer Inst 2002;94:652-61.

7. Spoelstra SL, Given CW. Assessment and measurement of adherence to oral antineoplastic agents. Semin Oncol Nurs 2011;27:116-32.

8. Spoelstra SL. Issues related to overadherence to oral chemotherapy or targeted agents. Clin J Oncol Nurs 2013;17:604-9.

9. Given B, Spoeltra SL, Grant M. The challenges of oral agents as antineoplastic treatments. Semin Oncol Nurs 2011;27:93-103.

10. Gadkari AS, McHorney CA. Unintentional non-adherence to chronic prescription medications: how unintentional is it really? BMC Health Serv Res 2012;14:98

11. Eliasson L, Clifford S, Barber N, et al. Exploring chronic myeloid leukemia patients' reasons for not adhering to the oral anticancer drug imatinib as prescribed. Leuk Res 2011;35:626-30.

12. Hugtenburg JG, Timmers L, Elders PJ, et al. Definitions, variants, and causes of nonadherence with medication: a challenge for tailored interventions. Patient Prefer Adherence 2013;10:675-82.

13. Horne R, Weinman J. Patients' beliefs about prescribed medicines and their role in adherence to treatment in chronic physical illness. $J$ Psychosom Res 1999;47:555-67.

14. Horne R, Chapman SC, Parham R, et al. Understanding patients' adherence-related beliefs about medicines prescribed for long-term conditions: a meta-analytic review of the Necessity-Concerns Framework. PLoS ONE 2013;2:e80633.

15. Pound $\mathrm{P}$, Britten N, Morgan M, et al. Resisting medicines: a synthesis of qualitative studies of medicine taking. Soc Sci Med 2005;61:133-55.

16. Roop JC, Wu H-S. Current practice patterns for oral chemotherapy: results of a national survey. Oncol Nurs Forum 2014;41:185-94.

17. Sommers RM, Miller K, Berry DL. Feasibility pilot on medication adherence and knowledge in ambulatory patients with gastrointestinal cancer. Oncol Nurs Forum 2012;39:E373-9.

18. Skott C. Expressive metaphors in cancer narratives. Cancer Nurs 2002;25:230-5.

19. Karnilowicz W. Identity and psychological ownership in chronic illness and disease state. Eur J Cancer Care 2011;20:276-82.

20. Strauss A, Corbin J. Basics of qualitative research: grounded theory procedures and techniques. Newbury Park, CA: Sage, 1990.

21. Japanese Gastric Cancer Association. Japanese classification of gastric carcinoma: 3rd English edition. Gastric Cancer 2011:14:101-12.

22. Center for Cancer Control and Information Services. Cancer Statics in Japan, 2013. http://ganjoho.jp/professional/statistics/backnumber/ 2013_jp.html (accessed 2 Aug 2014).

23. Wood $\mathrm{L}$. A review on adherence management in patients on oral cancer therapies. Eur J Oncol Nurs 2012;16:432-8.

24. Streubert Speziale HJ. Designing data generation and management strategies. In: Streubert Speziale HJ, Carpenter DR, eds. Qualitative research in nursing. 4th edn. Pennsylvania, PA: Lippincott Williams \&Wilkins, 2007:46-50.

25. Mathes T, Antoine SL, Pieper DC, et al. Adherence enhancing interventions for oral anti-cancer agents: a systematic review. Cancer Treat Rev 2014;40:102-8.

26. Kav S, Schulmeister L, Nirenberg A, et al. Development of the MASCC teaching tool for patients receiving oral agents for cancer. Support Care Cancer 2010;18:583-90.

27. Saratsiotou I, Kordoni M, Bakogiannis C, et al. Treatment adherence of cancer patients to orally administered chemotherapy: insights from a Greek study using a self-reported questionnaire. J Oncol Pharm Pract 2011;17:304-11.

28. Verbrugghe $\mathrm{M}$, Verhaeghe $\mathrm{S}$, Lauwaert $\mathrm{K}$, et al. Determinants and associated factors influencing medication adherence and persistence to oral anti-cancer agents: a systematic review. Cancer Treat Rev 2013;39:610-21.

29. Krolop L, Ko YD, Schwindt PF, et al. Adherence management for patients with cancer taking capecitabine: a prospective two-arm cohort study. BMJ Open 2013;3:e003139.

30. Clifforda S, Barbera N, Horne R. Understanding different beliefs held by adherers, unintentional nonadherers, and intentional 
nonadherers: application of the Necessity-Concerns Framework. J Psychosom Res 2008;64:41-6.

31. Harrow A, Dryden R, McCowan C, et al. A hard pill to swallow: a qualitative study of women's experiences of adjuvant endocrine therapy for breast cancer. BMJ Open 2014;13:1-10.

32. Pham MT. Emotion and rationality: a critical review and interpretation of empirical evidence. Rev Gen Psychol 2007;11:155-78.

33. Cramer P. Defense mechanisms in psychology today. Further processes for adaptation. Am Psychol 2000;55:637-46.

34. Reb AM. Transforming the death sentence: elements of hope in women with advanced ovarian cancer. Oncol Nurs Forum 2007;34: E70-81.

35. Ziner KW, Sledge GW, Bell CJ, et al. Predicting fear of breast cancer recurrence and self-efficacy in survivors by age at diagnosis. Oncol Nurs Forum 2012;1:287-95.

36. Efficace F, Rosti G, Cottone F, et al. Profiling chronic myeloid leukemia patients reporting intentional and unintentional non-adherence to lifelong therapy with tyrosine kinase inhibitors. Leuk Res 2014;38:294-8.

37. Leal I, Engebretson J, Cohen L, et al. Experiences of paradox: a qualitative analysis of living with cancer using a framework approach. Psychooncology 2015;24:138-46.

38. Horgan O, Holcombe C, Salmon P. Experiencing positive change after a diagnosis of breast cancer: a grounded theory analysis. Psychooncology 2011;20:1116-25.

39. Chi GC. The role of hope in patients with cancer. Oncol Nurs Forum 2007;34:415-24.

40. Sandsund C, Pattison N, Doyle N, et al. Finding a new normal: a grounded theory study of rehabilitation after treatment for upper gastrointestinal or gynaecological cancers-the patient's perspective. Eur J Cancer Care 2013;22:232-44.

41. Zolnierek KB, Dimatteo MR. Physician communication and patient adherence to treatment: a meta-analysis. Med Care 2009;47:826-34. 